\title{
Huge Adrenocortical Carcinoma: Case Report and Literature Review
}

\section{Maatougui Jasser ${ }^{1 *}$, Raboudi Mehdi ${ }^{1}$, Ben Rejeb Nedhir ${ }^{1}$, Besrour Chayma $^{1,2}$, Gargouri Faten ${ }^{3}$, Ramzi Khiari ${ }^{1}$, Ouertani Haroun ${ }^{2}$ and Ghozzi Samir ${ }^{1}$}

${ }^{1}$ Department of Urology, Military Hospital of Tunis, Tunis, Tunisia ${ }^{2}$ Department of Endocrinology, Military Hospital of Tunis, Tunis, Tunisia

${ }^{3}$ Department of Pathology, Military Hospital of Tunis, Tunis, Tunisia

*Corresponding Author: Maatougui Jasser, Department of Urology, Military Hospital of Tunis, Tunis, Tunisia.
Received: November 22, 2021

Published: December 15, 2021

(C) All rights are reserved by Maatougui Jasser., et al.

\begin{abstract}
Adrenocortical carcinoma is a rare entity. We report a case of a 47-year-old male with abdominal pain. without classical tumor symptoms. Computed tomography revealed a left adrenal mass measuring $17 \mathrm{~cm}$. Hormonal evaluation was negative. Open left adrenalectomy was performed by sub-costal approach. Diagnosis of adrenocortical carcinoma was established by pathology. Metastatic workup was negative. The patient has been followed regularly with no recurrence for one year. Adrenocortical carcinoma is a challenge. Surgery is the main treatment.
\end{abstract}

Keywords: Adrenocortical Carcinoma; Adrenalectomy; Mitotane

\section{Introduction}

Regarding the age of diagnostic patients, there is a bimodal destribution with a predilection for patients aged 5 and 20 years on the one hand and between 40 and 50 years on the other hand [1]. $60 \%$ of adrenocortical carcinoma were hormone-secreting [2]. Non-secreting masses were associated with a poorer prognosis because they were diagnosed at an evolved or metastatic stage, because of their insidious character [3].

In this study, we report a patient diagnosed as huge adrenocortical carcinoma treated by open adrenalectomy.

\section{Case Presentation}

Our patient is a 47-year-old male with isolated abdominal pain. Computed tomography showed a $17 \mathrm{~cm}$ enhancing mass, originated from left adrenal gland, with 30 Hounsfield units density, well encapsulated, and a wash-out less than $60 \%$, as showed in figure 1.

MRI revealed a tricompartmental mass arising from the left adrenal gland, with an area of hyperintensity in the centre and hyper-

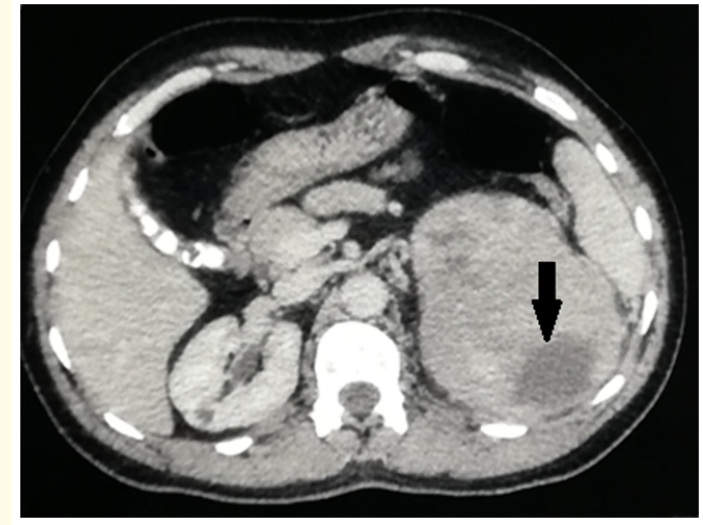

Figure 1: Intravenous contrast CT scan shows a $17 \mathrm{~cm}$ retroperitoneal mass in the left suprarenal area, with heterogeneous enhancement, Regions of non-enhancing tissue (arrow) are consistent with necrosis.

intensity and the upper and lower pole suggesting haemorrhage and necrosis as showed in figure 2 . 


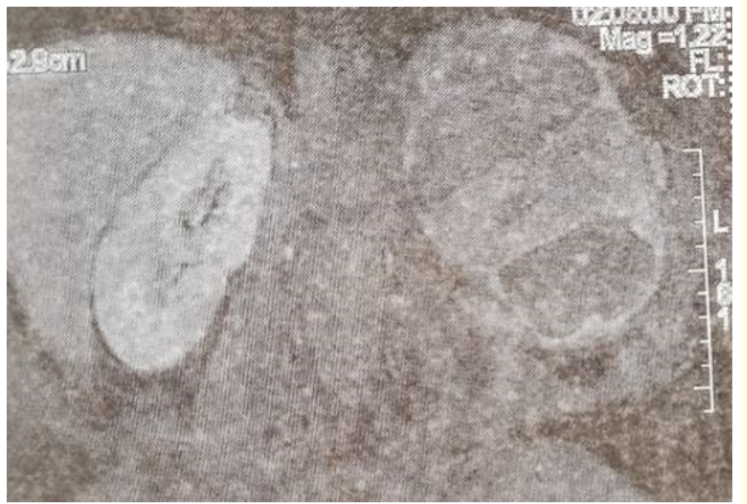

Figure 2: Coronal section of MRI showing the hetrogenous tricompartmental mass arising from the left adrenal gland.

Hormonal evaluation was negative, with normal ACTH and cortisol level. Suppression test was negative. Measurement of plasma renin activity and serum aldosterone levels showed no abnormalities. Plasmatic metanephrine and normetanephrine was also normal. Metastatic workup was negative.

A left subcostal adrenalectomy was performed. The mass was pushing the pancreas, spleen and left kidney with no evidence of organ invasion. No lymph nodes were found. After ligation of the adrenal vein, the mass was dissected and removed (Figure 3).

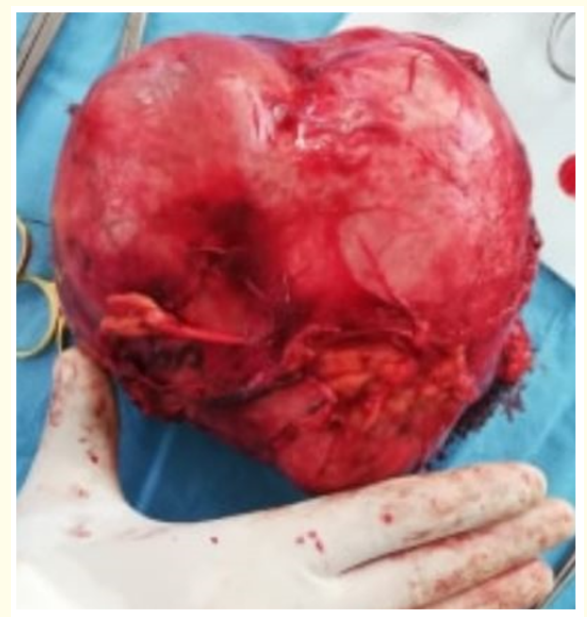

Figure 3: Surgical specimen showing a $17 \mathrm{~cm}$ well-encapsulated mass.
Histological examination showed $17 \times 15 \times 9 \mathrm{~cm}$ well-encapsulated, mass. The cross-section of the tumor (Figure 4) was tan-yellow and showed a tricompartmental aspect recalling the MRI findings.

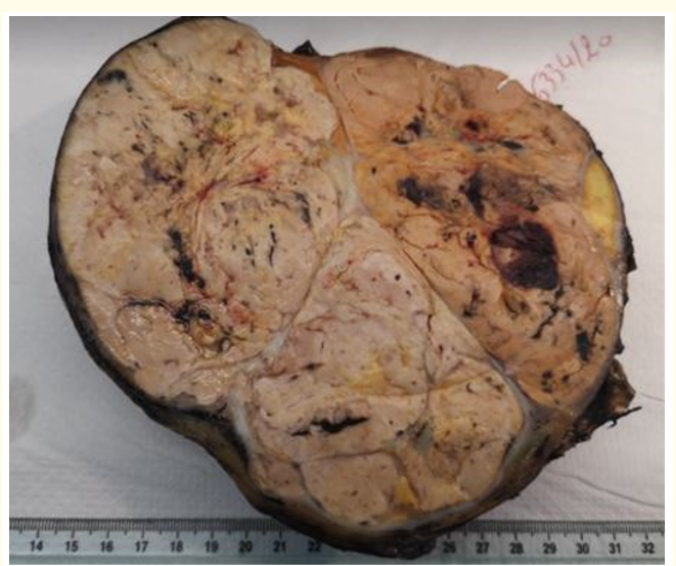

Figure 4: The cross-section of the $17 \mathrm{~cm}$ adrenal mass recalls the tricompartmental aspect noted in the MRI findings with haemorrhage and necrosis areas.

Histological examination of the tumor (Figure 5) showed overt features of malignancy.

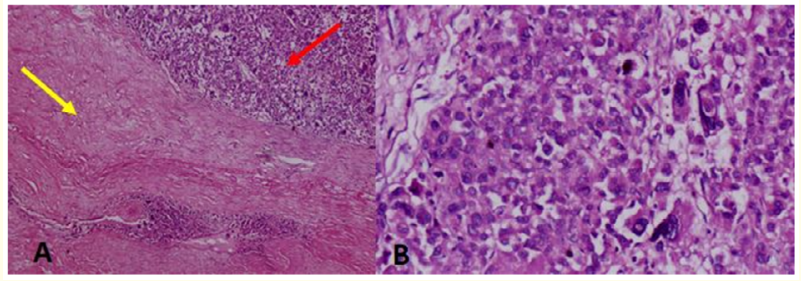

Figure 5: (A) Hematoxylin and eosin stain of the adrenal gland(x10) showing tumor cells (yellow arrow) and residual rim of normal adrenal gland (red arrow). (B) Hematoxylin and eosin stain of the tumor (x20), where the neoplastic cells show nuclear pleomorphism with multiple nuclei.

The diagnosis of adrenocortical carcinoma was confirmed. Postoperative recovery was uneventful. Our patient was discharged 4 days after surgery. The patient has been followed for one year with nor recurrence. 


\section{Discussion}

Adrenocortical carcinoma is a rare entity with a relatively bad prognosis [4]. A female predominance has been noticed [4]. Most patients with non-functional adrenocortical carcinoma present with advanced disease that is characterized by abdominal or extraabdominal metastatic masses, because they are diagnosed incidentally [5]. Approximately $60 \%$ of cases present clinical symptoms of hormonal secretion.. Hormone secretion may help to orient between benign and malignant adrenocortical masses [2].

Hormonal evaluation helps to define the functional character of the tumor and its origin. Imaging and especially computed tomography is sufficient can to define the size of the mass and metastatic work-up [6]. Tumors more than $4 \mathrm{~cm}$ must raise suspicion of malignancy. Surgery is the mainstream of treatment for localized stages and as soon as the tumor is extirpable [7]. As in our cases, we performed open radical adrenalectomy.

Postoperative surveillance for recurrence is primordial to early detect recurrence. It should be performed regularly for the first 2 years (every 3 months) and then for 5 years every 6 months. Contrast tomography is the standard imaging for follow-up [8].

In case of metastatic disease or recurrence after surgical exercise, the only treatment that can be used is mitotane [9].

Apart from the standard radiological examinations used to detect recurrence after surgery, certain biomarkers such as microRNAs, found in adrenal tissue, where its presence is considered by some authors as a biomarker of malignancy and/or recurrence [10].

\section{Conclusion}

Adrenocortical carcinoma is a rare malignancy.. Complete surgical excision is the mainstay of treatment especially in early stages. regular follow up plan should be established due to its high recurrence rate.

\section{Acknowledgement}

There were no individuals and organizations that have made substantive contributions to this manuscript.

\section{Bibliography}

1. Almarzouq A., et al. "Giant nonfunctioning adrenocortical carcinoma: a case report and review of the literature". BMC Research Notes 31 (2014): 7.
2. Patel VV., et al. "Giant non-functioning adrenocortical carcinoma: A rare childhood tumor". Indian Journal of Medical and Paediatric Oncology 31.2 (2010): 65-68.

3. Vassilopoulou-Sellin R and Schultz PN. "Adrenocortical carcinoma. Clinical outcome at the end of the $20^{\text {th }}$ century". Cancer 92 (2021): 1113.

4. Dehner LP and Hill DA. "Adrenal cortical neoplasms in children: Why so many carcinomas and yet so many survivors?" Pediatric and Developmental Pathology 12 (2009): 284-291.

5. Angeli A., et al. "Adrenal incidentaloma: An overview of clinical and epidemiological data from the National Italian Study Group". Hormone Research 47 (1997): 279-283.

6. Kapoor A., et al. "Guidelines for the Management of the Incidentally Discovered Adrenal Mass". Canadian Urological Association Journal 5.4 (2011): 241-247.

7. Zhou Z., et al. "Multidisciplinary team therapy for left giant adrenocortical carcinoma: A case report". World Journal of Clinical Cases 9.20 (2021): 5737-5743.

8. Schteingart DE., et al. "Management of patients with adrenal cancer: recommendations of an international consensus conference". Endocrine-Related Cancer 12 (2005): 667.

9. Kiesewetter B., et al. "Management of adrenocortical carcinoma: are we making progress?". Therapeutic Advances in Medical Oncology 13 (2021): 17588359211038409.

10. Mytareli C., et al. "The Diagnostic, Prognostic and Therapeutic Role of miRNAs in Adrenocortical Carcinoma: A Systematic Review". Biomedicines 9.11 (2021): 1501.

\section{Assets from publication with us}

- Prompt Acknowledgement after receiving the article

- Thorough Double blinded peer review

- Rapid Publication

- Issue of Publication Certificate

- High visibility of your Published work

Website: www.actascientific.com/

Submit Article: www.actascientific.com/submission.php

Emaill us: editor@actascientific.com

Contact us: +919182824667

Citation: Maatougui Jasser., et al. "Huge Adrenocortical Carcinoma: Case Report and Literature Review". Acta Scientific Medical Sciences 6.1 (2022):

151-153. 